\title{
The People's Two Rhythms: Charles Tilly and the Study of Contentious Politics. A Review Article
}

\author{
SIDNEY TARROW
}

\section{Cornell University}

In recent years, there has been an "event-ful return" in historical sociology and social history. Using new and swifter computational technologies, social scientists are employing systematic empirical methods to analyze population ecologies, social conflicts, and political struggles. This is no surprise-although the advances in computational technology have raised it to a new level of sophistication. But interpretive social scientists are focusing more on agency and actions too, promising a convergence-after years of growing distancebetween cliometrics and interpretation and between social and cultural history.

Nowheree more than in the study of contentious politics does the systematic study of events hold the greatest promise for the return of the actor to social historical practice. For classes of events ranging from revolutions to ethnic conflicts to strikes and protests, students of collective action are enumerating and analyzing events to study the scope and dynamics of social movements. But there is a danger of a new bifurcation: While some, like William Sewell, argue for a re-concentration on Great Events (1996a), others, like Susan Olzak, have used events as quantitative markers for structural processes (1989). Unless we are careful, sociologists working with historical materials and historians interested in social processes will proceed on parallel paths to the study of contentious politics with a wall of mutual ignorance between them.

In his recent book, Popular Contention in Great Britain, 1758-1834 (1995), Charles Tilly - who has trodden both paths - works towards a synthesis of quantitative and qualitative, long-term and shorter-term analysis of contention. But it was not always so. In this review, I will trace the progression of Tilly's work on contentious politics from The Vendée in the 1960s through his collaborative books of the 1970s and The Contentious French in the 1980s. I will first sketch the major emerging approaches to contentious politics, which I will call, with Sewell, "event-ful history" and, with Susan Olzak, "event history." I will then turn to the synthesis of these approaches that I argue Tilly has been moving towards for a number of years. The title of

${ }^{1}$ For a more detailed analysis of these strategies, see my "Contentious Event Research: Eventful History, Event Histories and Events-in-History" (1995).

$0010-4175 / 96 / 3767-2946 \$ 7.50+.10$ (C) 1996 Society for Comparative Study of Society and History 
this essay summarizes both the duality and the problems of Tilly's projectthe people's two rhythms.

\section{EVENTS, GREAT EVENTS AND EVENT HISTORIES}

The Oxford English Dictionary, or OED (Compact Edition, 1971:338) gives us the following as its main definition of the term, event:

The (actual or contemplated) fact of anything happening; the occurrence of. Now chiefly in phrase In the event of: in the case (something specified) should occur.

The OED doesn't stop there: A second meaning of the term is "anything that happens . . . an incident or occurrence"; a third is "that which follows upon a course of proceedings"; a fourth is "what becomes of or befalls (a person or thing" (1971:339); and a fifth is a combination of meanings two and three. A lot of meanings - and not all of them easily transmutable into empirical terms!

Historians have been no more univocal. Fernand Braudel looked down his Gallic nose at events as "surface disturbances, crests of foam that the tides of history carry on their strong backs" (1949, quoted in Appelby, Hunt, and Jacob 1994:83), while Olivier Dumoulins retrieved events from their Braudelian exile, calling the event "the historical fact that leaves a unique and singular trace, one that marks history by its particular and inimitable consequences" (1986:271). Philip Abrams gives the concept still more power when he writes that an event

is a transformation device between past and future. . . It is not just a happening there to be narrated but a happening to which cultural significance has successfully been assigned. . . . Events, indeed, are our principal points of access to the structuring of social action in time (Abrams 1982:191).

But just as Abrams and Dumoulins were moving away from the event-less macrohistory of the longue durée, a combination of postmodernist critics, anthropologized historians, and Foucauldian social constructionists were casting doubt on the ultimate reality of historical narrative from another angle. A healthy dose of relativism about the meaning of historical events was all that some of them wanted; but for others, all of history was narrative. Who made the French revolution? Not Lafayette, not the Abbé Sieyes, not Robespierre with his head rolling on the ground, not Marat lying in his bath with Charlotte Corday standing over him with a bloody knife! It was rather those who interpreted-nay, "imagined"- the French Revolution who created its current meaning. ${ }^{2}$ Events were secondary; social construction was all there was.

The problem with historical constructionism is not that historical events do not give rise to social constructions but that it shifted the focus of historical work from what happened to glosses on what happened, from context to text,

2 If my readers find this a caricature of social constructionist historiography, let them read Keith Michael Baker's Inventing the French Revolution (1990:especially 203-23). 
and away from the connections among "material conditions, shared identities, social relations, shared beliefs, memories, and experiences, collective interaction, and the reordering of power" (Tilly 1995:38-39) to interpretations. For the really strong constructionist, historical happenings became so much essentialist chaff which had to be threshed from the grain of a relativist history whose content was becoming more and more opaque.

But in recent years, there has been an "event-ful turn" away from both Braudelian macrohistory and postmodern deconstruction and towards something approaching Abrams' apotheosis of the event. Nowhere more than in the study of contentious politics does the turn to events bring promise for the return of the actor to social historical practice. There are two polar approaches to the analysis of events in recent historically based research on contentious politics.

In his "event-ful histories" approach, one that is closest to traditional historiography but which is much more self-consciously theoretical, William Sewell reacts explicitly against both the Annales school and radical deconstruction, making events the central subject of historical analysis but defining them in a special way that distinguishes them from ordinary occurrences. Sewell advises country-specificity, historical contingency and a focus on Great Events-like the taking of the Bastille (1996a) - which are the outcomes of great historical ruptures. He argues for a concentration on events that are on the cusp of historical change: both the outcomes of structural ruptures and the causes of sequences of cultural and political change that lead to new structural configurations.

The strong point of what Sewell proposes is to put events back at the center of structural and cultural change, while its weak point is that such an approach is insensitive to the sources of historical change that are not event-laden, as well as to those that result from cascades of small events that rarely, if ever, culminate in the Great Events he studies. Thus, the taking of the Bastille was indeed a liminal event with all the effects that Sewell ascribes to it; but can it be understood without referring to the slow, halting development of the routines of collective action employed by the people of Paris over the preceding decades?

In contrast to Sewell's proposal, event history scholars like Susan Olzak make classes of events the standardized data points in historical time series that they use as a measure of the effects of broader processes on human behavior. Olzak's work is relentlessly statistical, based on a conception of linear reality (Griffith and Isaacs 1989), and has gone further than any other scholar in relating variations in collective action empirically to time-wise measures of socio-economic processes. Her history is the history of contentious events, which she relates to one another in the degree to which they are compressed in time.

The strong point of the event history approach is in its power to relate forms 
of contentious politics systematically to the kind of non-event-ual processes that escape Sewell's Great Event approach, such as industrialization, immigration, the business cycle, variations in harvests or population growth and decline. Its weakness is the difficulty of relating sequences of events to noneventful variables like institutions, political processes and the importance of contingency that Sewell underscores. If these two approaches continue to proceed in parallel fashion over the same terrain of contentious politics, but from opposite sides of a methodological wall, it will be a great pity. Wherein lies the solution?

\section{EVENTS-IN-HISTORY}

In his recent Popular Contention in Great Britain, Charles Tilly proposes an alternative. Offering the closest thing we have to a synthesis of these opposed qualitative and quantitative approaches, Tilly embeds the events he studies in dynamic short-term sequences that intersect with both institutional politics and non-contentious events and with his favorite longer-term processes: capitalism and state building. The book not only commands our attention because of the immense effort that went into producing it but because it also attempts to combine the advantages of quantitative and qualitative, long-term and short-term approaches to the historical study of collective action and therefore proposes a solution to the bifurcation sketched above between eventful history and event histories.

Tilly's conception of events is not as self-consciously theoretical as Sewell's. Like Sewell, he focuses on historical sequences of events in relation to one another in particular historical configurations; but in contrast to Sewell, and like Olzak, he has fashioned a tool for the systematic enumeration and analysis of historical populations of events. The evolution of Tilly's approach has striven for a synthesis between sociology and history. I will call this synthesis "events-in-history," but before examining it, we need to understand how Tilly got to it. Two kinds of processes are important: the relationship of collective action to structural processes like urbanization, state building and capitalism; and the evolution of his conception and measurement of events.

\section{A. From The Vendée to The Contentious French}

Tilly's first study of collective action took him to the west of France (1964). In The Vendée, he developed a structurally based, theorized history in which urbanization was the fulcrum on which collective action against the Revolution turned. The account runs roughly like this: When the revolution comes into the hands of the urban bourgeoisie and its agents in the countryside, the urbanized Val-Samurois adapts to the changes, but the semi-urbanized Mauges produces opposition. The result is the variations in counterrevolutionary collective action between the two areas that Tilly traces in the empirical section of his book. 
Thus, it was something deeper than the anti-clerical policies of the Revolution and the forced conscription of young men into its armies that, for Tilly, produced counter-revolutionary activity. These events were the triggers for collective action, but their presence or absence can be accounted for by structural preconditions the importance of which in the Mauges is silhouetted by the contrast that Tilly makes between it and the Val-Saumurois. ${ }^{3}$ Much of the rest of Tilly's career has been occupied in illuminating the relations between such structural factors and contentious politics.

Tilly's next two efforts in the historical analysis of collective action turned more systematically to the analysis of events. He collected two masses of time-series data on France: the first on strikes from 1830 to 1968, the second on collective violence from 1830 to 1930 . The first resulted in a book coauthored with Edward Shorter (1974), while the second led both to two important co-authored articles ${ }^{4}$ and to his contribution to a three-nation comparative study, The Rebellious Century with Louise and Richard Tilly (1975). In both, Tilly moved from the analytical history of a Great Event like the Vendée rebellion to the systematic analysis of series of events-large and small, famous and insignificant - the movement of which over time was both interesting in itself and could be associated with the structural history of modern states.

But which structure? In these efforts in the 1970s, Tilly shifted from his original emphasis on urbanization as the structural matrix of collective action to the broader structural agencies of capitalism and state building. The former was the major driving force in the changes in strike behavior that he and Shorter studied in France, while changes in the character of political struggle were the major triggers for collective violence that he and his other collaborators found in The Rebellious Century. This was the origin of the "polity model" that appeared in Chapter Two of Tilly's text, From Mobilization to Revolution (1978), and the source of the growing emphasis on political struggle in all of his subsequent work.

These years marked a further shift in Tilly's research strategy from the brief temporal compass and broad variety of data sources he used in The Vendée to biting off much longer swaths of history and focusing on particular types of contention collected from more standardized sources. Tilly's turn to longer historical time series also co-occurred with his embrace of more rigorous empirical methods of event analysis. The lesson for historians was that the structurally based study of a "long-ish" durée did not lead to abandoning

\footnotetext{
3 In his critique of The Vendée, Sewell makes much of the fact that Tilly compares the two subregions as if they were points on a continuum of urbanization rather than different developmental types. But he hastens to add that this false teleology is not fatal: "It hid a masterwork of eventful sociology behind a veil of misconstrued universalizing science" (Sewell 1996b:13-15).

4 One with David Snyder on hardship and collective violence in France (1972) and the other with Abdul Lodhi on criminality and collective action (1971).
} 
l'histoire évenementielle but to dovetailing it with a correlational logic between events and structural change.

These were the years when Tilly came closest to becoming an event history sociologist in the mold of a Susan Olzak. This was true in two senses of the term: first, in collecting standardized records of similar forms of collective action which allowed him to relate his data to ongoing structural processes in a way that traditional narrative historians could not hope to do; and, second, because both of the studies he worked on in the 1970s focused on sociological processes, leaving him open to the charge of universalizing history (Sewell 1990).

As if in anticipation of this charge, the 1980s represented a return to historical narrative for Tilly - but to narrative of a most unusual kind. In The Contentious French, published in 1986, he extended his time frame from the hundred-odd years of his books in the 1970s to four hundred years of French history (his fondness for five-century blocs of time comes later), devoting each chapter of the book to the sweep of historical action in a particular region.

The Contentious French is innocent of the statistical elaborations that peppered Tilly's earlier work and returns to the practice of archival research with a vengeance. In preparing it, Tilly examined both national and departmental archives and employed standard narrative sources, but he was oddly casual about which historical events were featured and which were absent. Thus, a sequence of events in the same physical locale-like the Place de Grève in Paris-was allocated 20 pages, while the Revolution of 1848 got only 11 . Tilly's logic was structural, not event-ful, in Sewell's sense of the term: The Great Events that Tilly focused on were important because they helped him to trace secular changes in contention, not necessarily because they were great.

The two master processes which appeared in his earlier works-capitalism and state building-were once again asserted in The Contentious French as the major causes of the secular changes in collective action that he encountered. But he made no concerted effort at statistical association between them and the changes in collective action that he studied. These processes occur, as Sewell remarks, "off stage, outside of Tilly's texts, where they are essentially assumed as ever-present and ever-rising forces, a kind of eternal yeast" (Sewell 1996b). Other sources of French collective action-such as the religious wars that gave rise to a great deal of contention in the seventeenth centurywere part of the narrative, but they were given shorter theoretical shrift.

\section{THE REPERTOIRE OF CONTENTION}

Sewell's critique of Tilly's procedure in The Contentious French as "universalizing" was correct in one sense: Tilly was more interested in the play of broad structural processes, such as state building and capitalism, than in the distinct impact of such events as the French Revolution on the future of France 
(or of the world). But in another sense, Sewell's anti-universalist critique of Tilly's book is peculiar. For while Tilly abstracted from historical narrative to trace the impact of state building and capitalism on collective action, he also historicized and anthropologized the latter more thoroughly than any other contemporary theorist has done. ${ }^{5}$ In his work in the 1980 s, Tilly's major preoccupation was becoming the culture of collective action and how it changed.

The key concept was, of course, the "repertoire" of contention, which was laid out in a number of works but is theorized and operationalized most elaborately in Popular Contention in Great Britain, where it

helps describe what happens (in the ways that people act together in pursuit of shared interests) by identifying a limited set of routines that are learned, shared, and acted out through a relatively deliberate process of choice (1995:41-42).

Repertoires are not simply ways of doing things. They are learned cultural creations that result from the history of struggle:

People learn to break windows in protest, attack pilloried prisoners, tear down dishonored houses, stage public marches, petition, hold formal meetings, organize specialinterest associations (1995:42).

Sewell is critical of Tilly's supposed lack of attention to culture, but the concept of the repertoire is only a-cultural if culture is conceptualized as an abstract body of norms - in Tilly's withering terms, "like a numinous cloud hovering over social life, shifting in its own winds, and producing social action as rain or snow" (1995:40). If culture is conceived, instead, as the norms and practices which grow out of sets of social roles and interactions, then Tilly's conception of the repertoire is supremely cultural-for example, people's habits and expectations about how to do collective action; how it should be done, and what forms of collective action are likely to succeed.

What does this emphasis on repertoires mean for the event-filled history of collective action? At a minimum, it means that the systematic study of events over time-far from universalizing history and flattening it into a few master processes-becomes the mechanism for tracing the evolution of the culture of political struggle and of the impact of structural changes upon it. The concept of the repertoire is the most ambitious attempt we have to date to trace historically the changes in the character of collective action in connection with changes in society and politics.

\section{A. Honing the Instrument}

Increasingly since the early 1980s, and especially in Popular Contention in Great Britain, Tilly traced the various forms of contentious collective action

5 Contrast the treatment of the "collective action" problem in rational choice political science since Olson posed it in the 1960s. In this field, the character of collective action or its historical traditions do not figure at all. For a critique of the "history-less" image of collective action in collection action theory, see my Power in Movement (1994:ch. 1). 
over time, which is no inconsiderable achievement, given the obduracy and partiality of the historical record. He has done this, on the one hand, by abandoning the use of the official kinds of data, which seldom contain more than gross descriptions, for detailed newspaper data, and, on the other, by rejecting the economical but qualitatively questionable technique of measuring contentious events from newspaper headlines or indexes. ${ }^{6}$ Second, Tilly has broadened the boundaries of the events he studies from "protest," "violence," or strikes to the concept of the "contentious gathering," which he defines as

an occasion on which a number of people . . . outside of the government gathered in a publicly-accessible place and made claims on at least one person outside their own number, claims which if realized would affect the interests of their object (1995:63).

The definition takes in most events for which authorities and observers used such terms as "riot, disorder, disturbance, or affray" but also includes a great many "peaceful meetings, processions, and other assemblies that escaped the wrath of authorities" (1995:65). True, it ignores individual forms of resistance as well as the routine operation of institutionalized groups, except when these spill over into visible contention in the public arena. It is also insensitive to the incremental development of collective identities and of consensus mobilization which precedes contention because the public records on which his work is based tell us little about these cultural and social-psychological processes.

This choice is justified by Tilly's assumption that states of mind are neither univocal or measurable and that, therefore, more observable historical evidence must be sought. It also assumes, along with most event history scholars, that contention is important for its own sake and therefore is worth studying in its own right; and it argues that changes in collective action can be shown to relate to changes in the broader processes that Britain underwent during the period the study covers. (All of Chapter Three is devoted to charting those changes in broader processes, to industry and proletarianization, to state building and tax collection, to war and its aftermaths).

Enumerating and analyzing a large number of events does not enable thick description, but it does allow Tilly to compare the nature of contention in different times in Britain. ${ }^{7} \mathrm{He}$ and his group enumerated information about roughly 8,000 contentious gatherings from seven different British press sources and from the Acts and Proceedings of Parliament for Southeast England for a sample of thirteen years between 1758 and 1828 and for Britain as a whole for every year between 1828 and 1834 . This seventy-six year period,

6 For discussion of the sample, the procedures and the instrument, see Popular Contention (ch. 2 and Appendices). On the reliability of newspaper indexes for enumerating collective action events, see Olzak (1992:ch. 4 and Appendix).

7 In fact, Tilly concedes, "the method works better for comparison than for description" (1995:65). 
which included three major wars, the agitations over Wilkes, Queen Caroline, Catholic emancipation, and suffrage expansion, took place during the heroic phase of the industrial revolution; but this period also included thousands of rick burnings, machine breakings, forced illuminations, pulling down of houses, marches, petitions and demonstrations, and other less than Great Events, coded in standard form. ${ }^{8}$

\section{B. Old and New Repertoires}

Tilly's approach to the longue durée can be briefly, if inadequately, summarized in terms of how the repertoire of contention changed over time. People act collectively in ways that they understand, but at any point in time, they learn only a rather small number of alternative ways of acting collectively. The changes in the repertoire are therefore an observable litmus test of the changes in the modal interactions between citizens and their opponents-and thus of the character of popular struggle. When these interactions are organized in a sustained way around common interests, we are in the presence of social movements; when they are directed at the state, the national social movement has been invented. ${ }^{9}$

Repertoires can vary in a variety of ways. The best known-and the most criticized (Sewell 1990) - was the trichotomy between competitive, reactive and proactive collective action which Tilly left behind as a historical progression in the early 1980s. Replacing it in his thinking in Popular Contention is the distinction between two poles, each of which is seen as an adaptation to a different type of society, the one he found dominant in mid-eighteenth-century England and the one that had become more prominent there by the $1820 \mathrm{~s}$ and 1830s. The first is parochial, bifurcated, and particular:

It was parochial because most often the interests and interaction involved concentrated in a single community . . . bifurcated because when ordinary people addressed local issues and nearby objects they took impressively direct action to achieve their ends ... particular because the detailed routines of action varied greatly from group to group, issue to issue, locality to locality (1995:45).

The second is cosmopolitan, modular and autonomous:

They were cosmopolitan in often referring to interests and issues that spanned many localities or affected centers of power whose actions touched many localities... modular in being easily transferable from one setting or circumstance to another . . . autonomous in beginning on the claimants' own initiative and establishing direct communication between claimants and nationally-significant centers of power (1995:46, emphasis added).

\footnotetext{
${ }^{8}$ See Chapter 2 and Appendices of Popular Contention for Tilly's procedures, which differ from standard sociological practice in the extensive computer recording of textual data and the use of interactive computer technology to transform it into reduced word form for analysis.

${ }^{9}$ On the relationship between the repertoire and the development of the social movement, two of Tilly's articles lay out his conceptualization: "Speaking Your Mind" (1983) and "States and Social Movements" (1984).
} 
These changes are not teleological, Tilly insists, but a shift to a new set of tools adopted because "new users took up new tasks, and found the available tools inadequate to their problems and abilities. In the course of actual struggles, people making claims and counter-claims fashioned new means of claim-making" (1995:46). By studying real people engaged in actual struggles with others and against the state, Tilly traces the extent to which these changes show up in the historical record of contentious collective action and how they relate to his old friends, capitalism and state building.

The secular changes in British collective action do not walk through history wholly on their own feet: They correlate roughly with the growing centralization of the national state and the capitalization of the economy, which Tilly has charted statistically and narratively in Chapter Three of Popular Contention. But the reader will look in vain for a statistical test of the association between changes in capitalism and those in the nature of contentious gatherings assembled for this book. Capitalism only hovers in the background of his account, in part because Tilly has not included strikes in his enumeration but in part through an explicit choice: "For thirty years," he notes, "capitalism has dominated the discussion, and I want to redress the balance."10

The changes in the state are closer to the foreground of the analysis and can be seen operating in two directions - internal parliamentarization and external war making. Both show up dramatically in the changes in collective action, which, on the one hand, are increasingly directed at Parliament and, on the other, are triggered by war and by the strains of war financing. In particular, Tilly finds a strong shift from violent and parochial outbursts at the beginning of the period to the peaceful meetings and national claims towards its close, a shift which moves increasingly away from local and private targets and towards Parliament (1995:66).

But in arguing for the time-series correlation between parliamentarization and the adoption of a repertoire that is increasingly national, modular, and autonomous, Tilly stops well short of the canons of event history sociology because these correlations are only illustrated and are not demonstrated statistically through the logic of regression or formal modeling. " A major reason for this is that the small number of sample years studied (13 for the sample of years for Southeast England from 1758 to 1834 and 7 for the shorter national sample between 1828 and 1834) did not permit him to analyze statistically the relationship between the secular changes in British capitalism or state building and the up-and-down oscillations in collective action.

But there is also another reason for the lack of statistical estimation of the

10 In a personal communication to the author, Tilly commented on an earlier draft of this essay.

11 Tilly writes that he decided to foreswear the modeling and estimation of causal relationships in this book to disencumber the narrative, speak to historians of Britain, and give himself the discipline of laying out in words "what quantitative modeling will eventually have to represent, verify and falsify" (1995:75). 
relations between state building and collective action. Once Tilly demonstrated the overall shift in repertoires in the longish duree of the period from 1758 to 1834, he divides further treatment of the data into four discrete historical periods, rather than using the entire dataset for statistical analysis of the structural correlates of this change. 12 This division into periods of roughly twenty years (only one of them containing full yearly records) made it impossible to use statistical measures of association between capitalism, state building, and collective action. Why did Tilly do this? The answer helps to illuminate why I distinguish his approach from the strategies of eventful history and event histories.

\section{THE PEOPLE'S TWO RHYTHMS}

The four chapters of case studies shift the focus of Popular Contention in Great Britain from the longish durée of the initial conception to another logic: that of relating the incidents of popular collective action to the broader political histories of which they are a part-to institutional processes like parliamentary conflicts, to warmaking and tax collection, and to the rise of private associations and their role in particular campaigns and conflict. Tilly abandons the long period from 1758 to 1832 in order to construct sequences of events in something like the narrative tradition that Sewell would like us to revive.

Another way of putting the same point is stated by Tilly himself: People have two rhythms of collective action, he argues: "a jagged short-term rhythm depending heavily on shifts in the relative strategic positions, shared understandings, and resources of connected actors" and "a smoother long-term rhythm depending more heavily on the incremental transformation of social relations in the course of such processes as proletarianization and state formation" (1995:23). The longer-term changes in the repertoire are inscribed in the long-term rhythm of the secular changes in popular contention, but the narrative analysis of the different time periods in the book reflects Tilly's interest in their shorter one.

There are both costs and benefits in this procedure. In rooting his event analyses in specific configurations of time and space, Tilly gains the possibility of connecting popular contention to the political opportunity structures of each epoch, to the dominant strategies of state repression and reform, and to particular campaigns and cycles of protest. (It also makes the book more likely to be read by British historians, whose fondness for historical narrative left them impervious to Braudelian structuralism.) But by shifting to the shorter rhythm of popular contention in particular periods, Tilly sacrifices his

12 These are "The Era of Wilkes and Gordon" (1758-1788), "Revolution, War, and Other Struggles" (1789-1815), "State, Class and Contention" (1816-1827), and "Struggle and Reform" (1828-1834). 
ability to use the data to analyze statistically the overall relationships between state building, capitalization, and collective action. Instead, he repeats the original argument for period after period.

Why did Tilly go through the back breaking task of assembling computerized records on over 8,000 contentious gatherings for an eighty-year period and subjecting them to interminable interactive computing sessions? Why not, as Sewell seems to advise, select a Great Event which we already know is great and analyze it in its historical context, linking it through chains of contingent causation backward to crumbling structures and forward to the cultural construction of new ones? I think there are three answers. First, there is more than one potential book in any given dataset, particularly one that has been collected with such rigor and care. Given the fecundity of his past work, Tilly may already be thinking about the next one. Second, by selecting relatively short segments of political history for analysis and adding secondary data from other sources to his own quantitative data, Tilly can relate contentious events to other kinds of events, to non-eventful processes, and to what we know about the period from narrative history-exactly the kind of thickening of historical accounts that Sewell calls for. And third, even for such relatively short periods, the collection and analysis of records of collective events in a standard format allows us to configure connections in the history of a period that may not be evident to the naked eye or even to the trained historical mind.

One such set of connections is hinted at in the concept of "cycles of protest" that Tilly alludes to, but does not fully develop, in his chapter on the Reform period. Less momentous than revolutions, more connected than contingent chains of events, the concept of cycles studied through the systematic gathering of events data during short rhythms of ten to twenty year periods can allow us to interpret the connections among events and between them and noneventful processes and help us to understand the interactive progressions between structure and action. The collection of such dense collections of events can also help us to study the processes of diffusion in such cycles, and it can test the hypothesis, put forward by this reviewer (1994), that cycles are the crucibles from which innovations in the forms of the repertoire emerge.

Tilly's analysis of the reform period (from 1828 to 1834) goes furthest in this direction. It builds upon, and in some ways improves upon Hobsbawm and Rude's work on the Swing rebellion (1968) and anticipates and influenced my analysis of the cycle of protest in Italy (1989) and Kriesi and his collaborators' comparison of new social movements in Europe (1995). More important, it sets a possible course between the dangers of Great Event hagiography in Sewell's epistemology of "event-ful history" and the risks of statistical determinism in the model of "event histories" developed in the organizational tradition of American sociology by Susan Olzak. 


\section{PROVISIONAL CONCLUSIONS}

In closing, what can we say about Tilly's place in the rapidly expanding eventbased approach to the historical study of collective action and social movements? If there is an Occam's razor-like choice between Sewell's call for thick description of temporally ordered and structurally ruptural events and Olzak's rigorous statistical methodology, we will find it-if anywhere-in the synthesis between the structurally oriented long rhythms of Tilly's statistical comparisons and the politically sensitive short rhythms of the middle chapters of Popular Contention in Great Britain. In the still-young and rapidly changing state of research on historical collective action events, it is too soon to tell if others will attempt so bold a synthesis. Besides, as we have seen in other areas of sociology, the search for optimal methods too often evolves into right-way tests of orthodoxy which Tilly would be the last to recommend.

Event-ful history, event-history methods, and events-in-history offer three attractive alternatives to the case-study methods that have dominated the study of contentious politics in the past. Although they are each self-contained, they all hold promise for replicable, comparative, and cumulative research on collective action in modern societies. The danger is that these three approaches will drive those who adopt them into such different methods and perspectives that each group of specialists will proceed in blissful ignorance of the contributions of the others and the results of their accumulated research will not be truly cumulative. We must hope that none of the three careens off into so specialized a direction that they lose touch with practitioners of the other approaches.

Tilly's approach in Popular Contention has the advantage of framing his analysis within long rhythms that enable him to pick out patterns and identify secular changes in the repertoire and, within that framework, focus on shorter rhythms in which quantitative and qualitative analysis can be combined and the changes in the repertoire are related to specific events and processes.

A final note, one which will have to remain no more than a whisper: None of the three approaches I have sketched directly confronts the relationship between contentious politics and social movements. Tilly, who comes closest to formulating this relationship theoretically, regards movements as a form of collective action - a point on a typology consisting of the scope of action and the orientation to power holders. But if this is the case, are movements observable events, in the same sense that we observe some of the other actions in his concept of the repertoire-the forced illumination, the charivari, the march, and the demonstration? Or is a movement an actor or coalition of actors whose presence can be traced through collective action and the combination of collective actions which typify it or them but which is not reducible to a form in the repertoire? If the former is the case, then we need to understand how the social movement relates to the other forms of action from which 
Tilly distinguishes them; if the latter, then we need to theorize explicitly how we expect movements to look, when what we see of them is only their public face. This is a question that Tilly has left tantalizingly unanswered: But, given the rate at which new concepts and theories flow from his pen, we will not have long to wait for his response.

\section{REFERENCES}

Abrams, Philip. 1982. Historical Sociology. Ithaca: Cornell University Press. Anderson, Benedict. 1991. Imagined Communities. London: Verso.

Appelby, Joyce; Lynn Hunt; and Margaret Jacobs. 1994. Telling the Truth About History. New York: Norton.

Baker, Keith Michael. 1990. Inventing the French Revolution: Essays on French Political Culture in the Eighteenth Century. Cambridge: Cambridge University Press.

Dumoulins, Olivier. 1986. "Evenementielle (Histoire)," in André Burguière, ed., Dictionnaire des sciences historiques, 271-2. Paris: Presses Universitaires de France.

Favre, Pierre, ed. 1990. La Manifestation. Paris: Presses de la Fondation Nationale des Sciences Politiques.

Fillieule, Olivier. 1994. "Contribution à Une Théorie Compréhensive de la Manifestation: Les formes et les déterminants de l'action manifestante dans la France des années quatre-vingts." Unpublished doctoral thesis, Institut d'Etudes Politiques, Paris.

Hobsbawm, Eric; and George Rudé. 1968. Captain Swing. New York: Norton.

Isaac, Larry W.; and Larry J. Griffin. 1989. "Ahistoricism in Time-Series Analyses of Historical Process: Critique, Redirection, and Illustrations from U.S. Labor History" American Sociological Review, 54:6, 873-90.

Kriesi, Hanspeter, et al. 1995. The Politics of New Social Movements in Western Europe. Minneapolis: University of Minnesota Press.

Lohdi, A. Q.; and Charles Tilly. 1973. "Urbanization, Criminality, and Collective Violence in Nineteenth-Century France." American Journal of Sociology, 79:2, 296-318.

Olivier, Johan. 1989. "Dynamics of Ethnic Collective Action in South Africa, 19701984." PhD disser., Department of Sociology, Cornell University.

Olzak, Susan. 1989. "Analysis of Events in Studies of Collective Action." Annual Review of Sociology, no. 15:119-41.

1992. The Dynamics of Ethnic Competition and Conflict. Stanford: Stanford University Press.

Rucht, Dieter; and Friedhelm Neidhardt. 1995. "Methodological Issues in Collecting Protest Event Data: Units of Analysis, Sources and Sampling, Coding Problems." Presented to the Workshop on Protest Event Analysis," Wissenschaftszentrum, Berlin.

; and Thomas Ohlemacher. 1992. "Protest Event Data: Collection, Uses and Perspectives," in Mario Diani and Roy Eyerman, eds., Studying Collective Action, 76-106. Newbury Park, CA: Sage Publications.

Sewell, William H., Jr. 1990. "Collective Violence and Collective Loyalties in France: Why the French Revolution Made a Difference." Politics and Society, 18:4, 527-52. 1996a. "Historical Events as Structural Transformations: Inventing Revolution at the Bastille." Theory and Society. (In press).

1996b. "Three Temporalities: Towards an Eventful Sociology," in Terrence J. 
MacDonald, ed. The Historic Turn in the Human Sciences. Ann Arbor: U. of Michigan Press.

Shorter, Edward; and Charles Tilly. 1974. Strikes in France, 1830 to 1968. London: Cambridge University Press.

Snyder, David; and Charles Tilly. 1972. "Hardship and Collective Violence in France, 1830-1960." American Sociological Review, 37:5, 520-32.

Soule, Sarah Anne. 1995. "The Student Anti-Apartheid Movement in the United States: Diffusion of Protest Tactics and Policy Reform." Unpublished thesis.

Stone, Lawrence. 1979. "The Revival of Narrative: Reflections on a New Old History." Past and Present. no. 5 (November), 3-24.

Tarrow, Sidney. 1987. "Big Structures and Contentious Events: Two of Charles Tilly's Recent Writings.” Sociological Forum, 2:1, 191-204.

1989. Democracy and Disorder. Protest and Politics in Italy, 1965-1974.

Oxford: Oxford University Press.

1994. Power in Movement: Social Movements, Collective Action and Politics.

Cambridge: Cambridge University Press.

1995. "Contentious Event Analysis: Eventful History, Event Histories and

Events-in-History." Presented at the Workshop on Collective Action Research, June 12-15, Wissenschaftszentrum, Berlin.

Tartakowsky, Danielle. 1986. "Stratègies de la rue 1934-1936." Le Mouvement Social, 135 (April-June), 31-62.

1994. "Les Manifestations de rue en France, 1918-1968." Thèse d'Etat,

Université de Paris I.

Tilly, Charles. 1964. The Vendée. Cambridge, MA: Harvard University Press. 1978. From Mobilization to Revolution. Englewood Cliffs, NJ: Prentice-Hall. 1981. As Sociology Meets History. New York: Academic Press.

1983. "Speaking Your Mind Without Elections, Surveys, or Social Move-

ments." Public Opinion Quarterly, 47:4,461-78.

1984. "Social Movements and National Politics," in C. Bright and S. Hard-

ing, eds., Statemaking and Social Movements: Essays in History and Theory, 297-

317. Ann Arbor: University of Michigan Press.

1986. The Contentious French. Cambridge, MA: Harvard University Press. 1993. European Revolutions, 1492-1992. London: Blackwell's.

1995. Popular Contention in Great Britain. Cambridge, MA: Harvard University Press.

; and Leopold Haimson, eds. 1989. Strikes, Wars and Revolutions in an International Perspective. Cambridge: Cambridge University Press.

; Louise Tilly; and Richard Tilly. 1975. The Rebellious Century, 1830-1930.

Cambridge, MA: Harvard University Press.

Touraine, Alain. 1988. The Return of the Actor. Social Theory in Postindustrial Society. Cambridge: Cambridge University Press.

Traugott, Marc, ed. 1995. Cycles and Repertoires of Collective Action. Durham, NC:

Duke University Press. 